\title{
Trypanosoma vivax Adhesion to Red Blood Cells in Experimentally Infected Sheep
}

\author{
Alpidio A. Boada-Sucre, ${ }^{1}$ Marcello Salvatore Rossi Spadafora, ${ }^{2,3}$ \\ Lucinda M. Tavares-Marques, ${ }^{4}$ Héctor J. Finol, ${ }^{5}$ and Armando Reyna-Bello ${ }^{4,6}$ \\ ${ }^{1}$ Laboratorio de Microscopía Electrónica, Centro de Estudios Biomédicos y Veterinarios, Instituto de Estudios Científicos y Tecnológicos, \\ Universidad Nacional Experimental Simón Rodríguez, Caracas, Venezuela \\ ${ }^{2}$ Unidad de Toxoplasmosis y Protozoosis, Departamento de Parasitología, Centro Nacional de Microbiología, \\ Instituto de Salud Carlos III, Calle Alejandro Casona 7, Piso 6D, 28035 Madrid, Spain \\ ${ }^{3}$ Sección de Inmunohistoquímica y Microscopía Electrónica, Instituto Anatomopatológico "José A. O’Daly", \\ Facultad de Medicina, Universidad Central de Venezuela, Caracas, Venezuela \\ ${ }^{4}$ Grupo de Inmunobiología, Centro de Estudios Biomédicos y Veterinarios, Instituto de Estudios Científicos y Tecnológicos, \\ Universidad Nacional Experimental Simón Rodríguez, Caracas, Venezuela \\ ${ }^{5}$ Centro de Microscopía Electrónica "Mitsuo Ogura", Facultad de Ciencias, Universidad Central de Venezuela, Caracas, Venezuela \\ ${ }^{6}$ Investigador Prometeo, Universidad de Las Fuerzas Armadas ESPE, Departamento de Ciencias de la Vida, \\ Grupo de Investigación de Sanidad Animal y Humana (GISAH), Sangolquí, Ecuador
}

Correspondence should be addressed to Marcello Salvatore Rossi Spadafora; rossimarcell@gmail.com

Received 28 October 2015; Accepted 30 March 2016

Academic Editor: Piero Tosi

Copyright (C) 2016 Alpidio A. Boada-Sucre et al. This is an open access article distributed under the Creative Commons Attribution License, which permits unrestricted use, distribution, and reproduction in any medium, provided the original work is properly cited.

\begin{abstract}
Trypanosomosis, a globally occurring parasitic disease, poses as a major obstacle to livestock production in tropical and subtropical regions resulting in tangible economic losses. In Latin America including Venezuela, trypanosomosis of ruminants is mainly caused by Trypanosoma vivax. Biologically active substances produced from trypanosomes, as well as host-trypanosome cellular interactions, contribute to the pathogenesis of anemia in an infection. The aim of this study was to examine with a scanning electron microscope the cellular interactions and alterations in ovine red blood cells (RBC) experimentally infected with $T$. vivax. Ovine infection resulted in changes of RBC shape as well as the formation of surface holes or vesicles. A frequent observation was the adhesion to the ovine RBC by the trypanosome's free flagellum, cell body, or attached flagellum in a process mediated by the filopodia emission from the trypanosome surface. The observed RBC alterations are caused by mechanical and biochemical damage from host-parasite interactions occurring in the bloodstream. The altered erythrocytes are prone to mononuclear phagocytic removal contributing to the hematocrit decrease during infection.
\end{abstract}

\section{Introduction}

In Venezuela, trypanosomosis, a globally occurring parasitic disease, in animals is mainly caused by Trypanosoma vivax. Trypanosomosis is responsible for tangible economic losses due to impaired livestock production. The detrimental effects produced by T. vivax in livestock include growth retardation, loss of body weight, low production of animal proteins (meat and milk) [1,2], and diminished fertility [3]. These effects are responsible for increasing production costs through an increased need for treatment and veterinary care [4-6].
The economic implications of trypanosomosis in developing subtropical regions underscore the value in research covering the pathogenesis of T. vivax.

Animal trypanosomosis is characterized by periodic fevers, parasitemia, and anemia, changes in blood chemistry, body mass loss, and often death. The anemia developed by animals is considered the most characteristic symptom [7]. It seems that the anemia is hemolytic in nature, intravascular in the early stages of the disease, and extravascular in the chronic phase $[6,8]$. 
Current experimental and clinical evidence on animal trypanosomosis suggests that the main pathogenetic mechanisms of anemia include hemolysis, red blood cells (RBC) sequestration, hemodilution, platelet aggregation, lipid peroxidation, bleeding, and bone marrow dysfunction $[9,10]$. However, insufficient research has been done to associate the structural and biochemical changes in RBCs as consequences of the interaction between RBC and trypanosomes. For example, existing reports list the following as possible mechanisms responsible for RBC injury: mechanical damage produced by the interaction of trypanosomes with $\mathrm{RBC}$ [11], adhesion and membrane fusion mediated filopodia [12], immune complexes adsorbed to erythrocytes [13], and biologically active substances released by live or dead trypanosomes which produce erythrocyte injury [14-17].

In Venezuela, T. vivax is the causative agent of trypanosomosis in ruminants. The pathogenesis, characterized by anemia and fever, seriously compromises the animal's health $[1,6,18]$. The aim of this study was to examine, with a scanning electron microscope (SEM), the cellular interactions and alterations in ovine RBCs experimentally infected with a Venezuelan T. vivax isolate.

\section{Material and Methods}

2.1. Experimental Animals. A total of nine (9) crossbreed male sheep in reproductive age (30-35 kg body weight) were used in the study. Two of them were used as control and seven as the experimental group. Sheep in the experimental group were randomly selected and inoculated simultaneously with strain LIEM-176 of T. vivax. Both groups were housed in separate corrals covered with antimosquito nets to prevent contact with blood sucking flies and disease vectors. All the animals were fed concentrated food (Purina ${ }^{\circledR}, 500 \mathrm{~g} /$ animal/day), hay, and water ad libitum.

Both groups were clinically, parasitologically, and PCR examined one week before starting the study (preinfection period) in order to confirm the negativity to T. vivax and other hemoparasites. All tests were conducted at the Instituto de Estudios Científicos y Tecnológicos under veterinary supervision.

2.2. Trypanosomes. The strain LIEM-176 of T. vivax used in this work was previously morphometric and molecularly characterized [19-21], isolated from naturally infected cattle in the Trujillo State (Venezuela), and kindly provided by Drs. Glenda Moreno and Laura Moron of Universidad de Los Andes and expanded by inoculation into sheep.

2.3. Experimental Infection of Sheep. One $\mathrm{mL}$ of blood containing approximately $1 \times 10^{6}$ blood trypomastigotes of T. vivax was inoculated intravenously in the jugular vein of each sheep of the experimental group. Control animals were inoculated with $1 \mathrm{~mL}$ of isotonic saline solution. Once inoculated, experimental and control groups were clinically and parasitologically examined every 4 days for 45 days. Values collected as indicators of T. vivax infection included the temperature, hematocrit, total plasma proteins, hemoglobin, and parasitemia by the Brener method [22].
During experimental infection, all animals were maintained under veterinary supervision to safeguard health and minimize animal suffering. Protocols used were approved by the Ethical Committee for Laboratory Animal Use under number 013-11 according to the Ethics Chart of animal experimentation.

2.4. Scanning Electron Microscopy (SEM). Aliquots of blood from sheep experimentally infected with $T$. vivax taken every 4 days from the jugular vein (Vacutainer System ${ }^{\circledR}$ ) and prefixed with Karnovsky fixative solution $(2.5 \%$ glutaraldehyde and $4 \% p$-formaldehyde in Millonig's phosphate buffer $0.10 \mathrm{M}, \mathrm{pH} 7.4$ ) were contained in vacuum-glass tubes of $5 \mathrm{~mL}$. The blood fixation process was done following the technique described by Boada-Sucre et al. [23]. Briefly, fixation began at the time of blood sampling for 1 hour at $4^{\circ} \mathrm{C}$. Finally, $100 \mu \mathrm{L}$ of prefixed blood was spotted on to coverslips pretreated with poly-L-lysine $0.1 \% \mathrm{v} / \mathrm{v}$ in order to promote the adhesion of blood cells. The excess of glutaraldehyde was removed by washing with Millonig's phosphate buffer and the postfixation was performed with $1 \% \mathrm{~m} / \mathrm{v}$ osmium tetroxide $\left(\mathrm{OsO}_{4}\right)$ for 1 hour at $4^{\circ} \mathrm{C}$. Osmium excess was removed by washing with deionized water and samples were dehydrated in increasing concentrations of ethanol at $4^{\circ} \mathrm{C}$. The biological material adsorbed to the coverslips was dried by evaporation on a critical point dryer (Hitachi HCP2) using carbon dioxide $\left(\mathrm{CO}_{2}\right)$ as liquid transition fluid. Then, samples were mounted on the sample holder and covered with platinum ion (Electron Microscopy Science EMS-350). Observations and micrographic records were performed on a field emission scanning electron microscope (FE Hitachi S-4500) with an accelerating voltage of $5 \mathrm{keV}$.

2.5. Transmission Electron Microscopy (TEM). The liver samples were processed for TEM using the standard methods described by Boada-Sucre et al., 1999 [23]. Pieces of liver were fixed at $2 \mathrm{~mm}$ in diameter with glutaraldehyde $2.5 \%$ and $\mathrm{OsO}_{4}$ 1\% (Millonig-buffered solutions pH 7.4; 300 mOsm), dehydrated in increasing ethanol concentrations, and embedded in Epon 812. Sections were cut with a diamond knife in a RMC Ultramicrotome MT 7.000, and stained with uranyl acetate and lead citrate. Sections were observed with a Hitachi H7100 transmission electron microscope $(75 \mathrm{kV}$ accelerating voltage).

2.6. Statistical Analysis. Each SEM preparation was examined 15,30 , or 45 days after infection. For each SEM preparation, one hundred trypomastigotes were counted and the proportion of observed parasite-RBC adhesion was quantified. For the adhered trypomastigotes, the method of adhesion was counted; the proportion of cell body adhesion, free flagellum adhesion, and attached flagellum adhesion was calculated. The proportions of T. vivax adhesion and the cell body structures involved in the attachment were compared using a two-tailed Fisher's Exact Test at a 95\% confidence level. Differences between observations were considered statistically significant when $p<0.05$. 


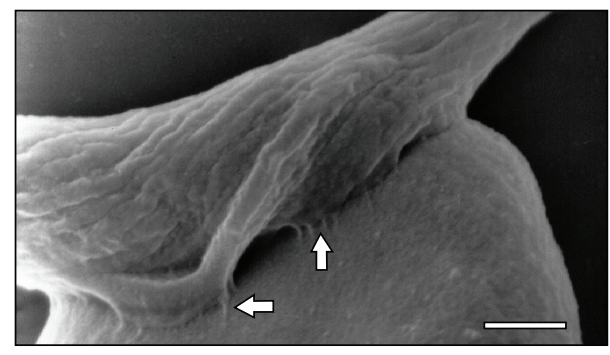

FIGURE 1: Scanning electron micrograph showing a large area $(\Rightarrow)$ of T. vivax in close contact to sheep erythrocytes at 30 days after infection. Bar $=1.2 \mu \mathrm{m}$.

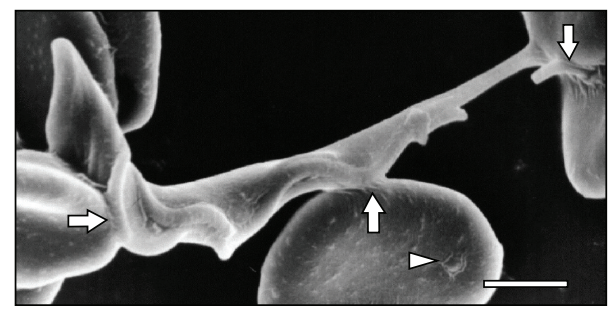

Figure 2: Adhesion of T. vivax to three RBCs through its body and flagellum $(\Rightarrow)$. Note the presence of a vesicle $(\triangle)$ in one RBC at 15 days after infection. Bar $=1.4 \mu \mathrm{m}$.

\section{Results}

Scanning electron microscopy showed the interaction of T. vivax with sheep RBCs. The interactions of $T$. vivax trypomastigotes with RBCs from experimentally infected sheep can be observed in the scanning electron micrographs of Figures 1-11. As it can be observed, the interaction was achieved through the establishment of a very narrow cell contact and the subsequent development of RBC clusters. This adhesion was favored by the emission of filamentous and membranous projections through the trypanosome cell body (Figure 1). Figures 2-6 show RBC adhesion mediated by the attached T. vivax flagellum. Free flagellum participation is observed in Figures 3 and 7-9, while the direct involvement of $T$. vivax cell body is shown in Figures 1, 2, and 9-11. This interaction between $T$. vivax and RBCs was measured as the proportion of $T$. vivax adhered at 15,30 , or 45 days after infection and is summarized in Table 1.

The proportion of adhered trypomastigotes at 15 days after infection is significantly higher than the proportion at 30 and 45 days after infection according to Fisher's Exact Test $(p<0.001)$. There was no significant difference between 30 and 45 days after infection (Table 1). Moreover, the parasite segments (cell body, free flagellum, and attached flagellum) adhered to the RBCs were quantified and the proportions were examined 15, 30, and 45 days after infection (Table 2).

Trypomastigotes adhered to sheep RBCs through the free flagellum at any time after infection are significantly higher $(p<0.0001)$ than the cell body and attached flagellum. Furthermore, the proportion of trypanosomes adhered to $\mathrm{RBC}$ through the attached flagellum is significantly lower

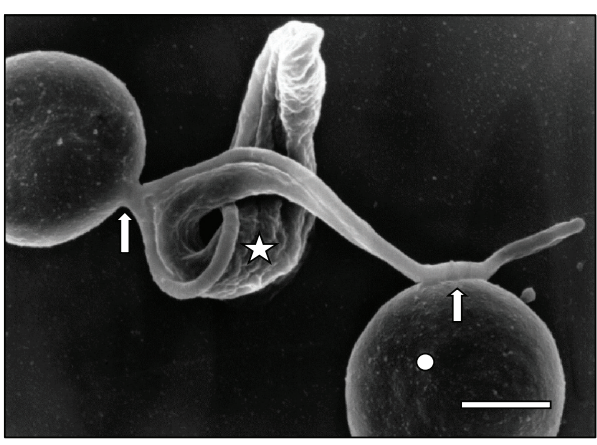

Figure 3: Attached $(\Rightarrow$ ) trypanosome ( $₫$ ) to two sheep RBCs $(\bigcirc)$ at 30 days of infection. Bar $=1.4 \mu \mathrm{m}$.

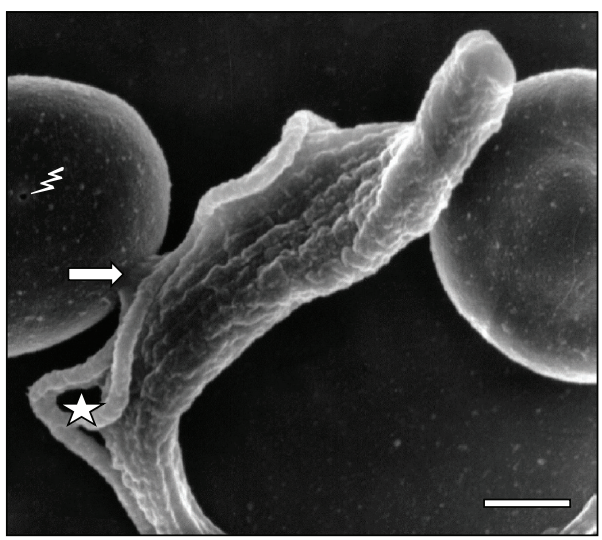

FIGURE 4: High resolution of a parasite in division process (i ) and contact $(\Rightarrow)$ with an erythrocyte sheep at 45 days of infection. Note the holes in $\mathrm{RBC}(\xi)$. Bar $=2.0 \mu \mathrm{m}$.

$(p<0.0001)$ than the proportion of parasites adhered through the cell body.

The proportion of trypanosomes adhered to sheep RBC through the flagellum was very significant at day 15 when it was compared with the adhesion observed at days 30 and 45 $(p<0.0001)$. In addition, trypanosomes adhered through the cell body was significantly higher $(p<0.0001)$ at 15 and 45 days after infection, while the proportion of parasites adhered through the attached flagellum was significantly lower $(p<$ 0.0001 ) at days 15 and 45 after infection.

Additionally, SEM images depict the emission of filopodia by $T$. vivax during the experimental infection process (Figure 10). The interaction of bloodstream trypanosomes with RBCs induces vesicle formation (Figure 2). Moreover, SEM images show pore formation on the erythrocyte surface during experimental infection (Figures 4, 9, and 12). Other common findings were morphological alterations in $\mathrm{RBC}$ (Figures 13 and 14), activated white blood cells (WBC) (Figure 15), WBC in contact with RBC (Figures 14 and 16), microspherocytosis (results not showed), and erythrophagocytosis process extravascularly (Figure 17) and intravascularly in liver sinusoid (Figure 18). 


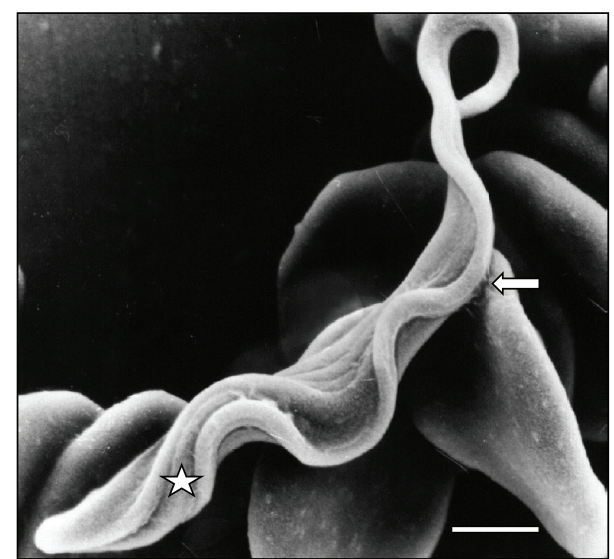

FIGURE 5: Scanning electron microscopy of adhesion $(\Rightarrow)$ from one parasite in division ( $(\xi)$ to sheep erythrocyte at 45 days of infection. $\operatorname{Bar}=2.0 \mu \mathrm{m}$.

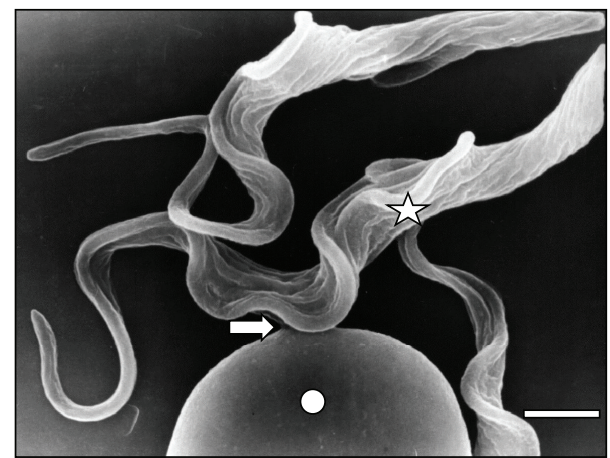

FIgURE 6: Electron microscopy of adhesion $(\Rightarrow)$ of T. vivax in division ( $₫)$ to a sheep RBC $(\bigcirc)$ through the attached flagellum at 30 days of infection. Bar $=2.0 \mu \mathrm{m}$.

\section{Discussion}

In the RBC-Trypanosoma adhesion observed by SEM, morphological changes in the RBCs are found to be a contributing factor in the pathophysiology of anemia in sheep trypanosomosis by T. vivax.

In this paper, we have described the adhesion between T. vivax and sheep RBC mediated by the parasite's cell body, attached flagellum, and free flagellum. Free flagellum adhesion appears to be favored by the emission of filopodia and filamentous material of parasitic origin. Similar observations were reported between T. brucei and T. evansi to murine RBC $[12,13]$.

This adhesion of T. vivax to sheep RBC led to notable observations. First, Table 1 shows higher adhesion during the early stage of the disease compared to the latest stage, suggesting that the adhesion of T. vivax to $\mathrm{RBC}$ is inhibited by the sheep's antibodies against the parasite membrane. As it was described as a capping effect in T. evansi, mediated by antibodies [24].

Next, Table 2 shows higher adhesion of T. vivax to RBC through free flagellum than cell bodies or attached flagellum.

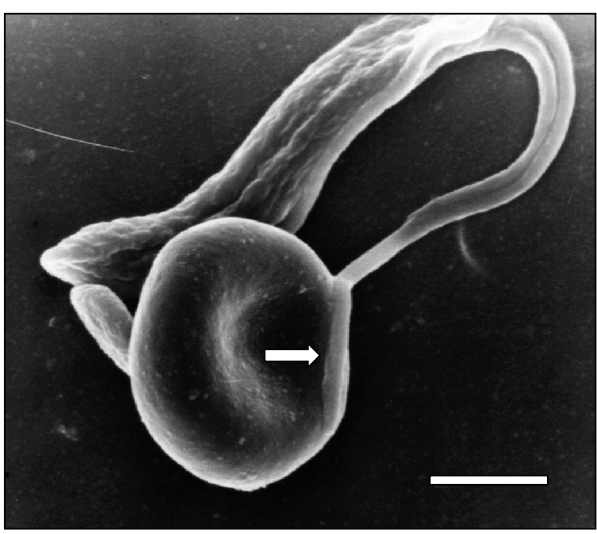

Figure 7: T. vivax flagellum contact $(\Rightarrow)$ with a RBC at 15 days of inoculation. $\operatorname{Bar}=1.7 \mu \mathrm{m}$.

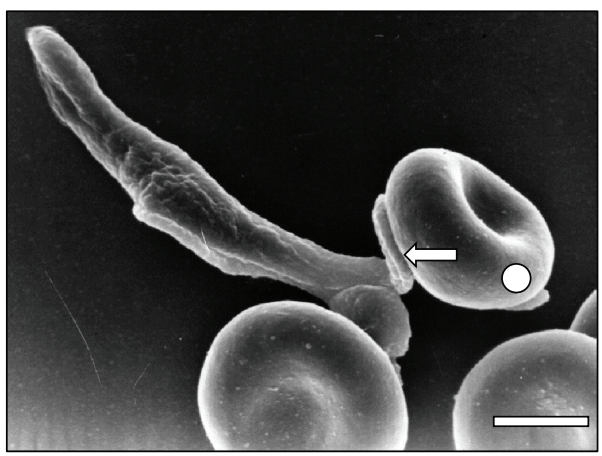

FIGURE 8: Scanning electron micrographs showing a large area of $T$. vivax flagellum in close adhesion $(\Rightarrow)$ to a sheep erythrocyte $(\bigcirc)$ at 30 days after infection. $\mathrm{Bar}=1.6 \mu \mathrm{m}$.

TABLE 1: Percentage (\%) of trypanosomes adhered to RBC or free, during infection process.

\begin{tabular}{lcc}
\hline Days after infection & $\begin{array}{c}\text { \% of T. vivax } \\
\text { adhered to RBC }\end{array}$ & $\begin{array}{c}\text { \% of T. vivax } \\
\text { nonadhered to RBC }\end{array}$ \\
\hline 15 & 40 & 60 \\
30 & 38 & 62 \\
45 & 38 & 62 \\
\hline
\end{tabular}

TABLE 2: Percentage (\%) of trypanosomes adhered to RBC through cell body, flagellum, and attached flagellum during infection process.

\begin{tabular}{lccc}
\hline $\begin{array}{l}\text { Days after } \\
\text { infection }\end{array}$ & Cell body & Free flagellum & Attached flagellum \\
\hline 15 & 12 & 20 & 8 \\
30 & 11 & 18 & 9 \\
45 & 12 & 18 & 8 \\
\hline
\end{tabular}

This difference is remarkable since it may be due to the free flagellum's continuous whiplash movement.

The emission of filopodia by the African trypanosomes has been described by several researchers since the 1970s in infections caused by T. b. brucei and T. b. rhodesiense [25] and African isolates of T. vivax [26] and T. venezuelense (T. evansi) 


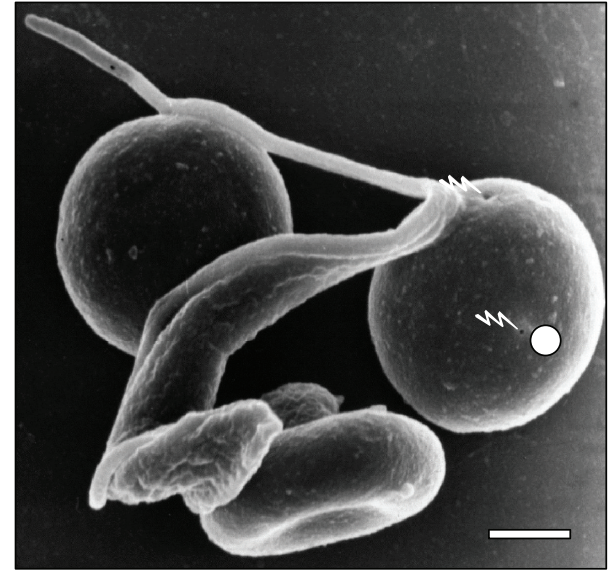

FIgURE 9: Scanning electron micrograph showing the adhesion of a T. vivax bloodstream trypomastigote to two sheep RBCs $(O)$ with holes $(\xi)$ at 45 days of infection. The adhesion was through free flagellum and cell body. Bar $=2.0 \mu \mathrm{m}$.

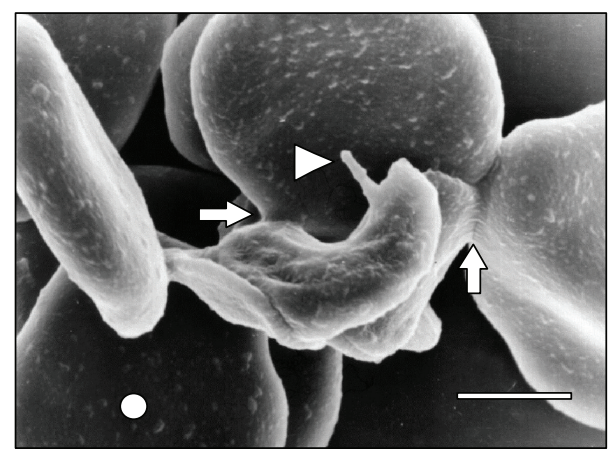

FIgURE 10: Trypomastigote in a close contact to a RBC cluster (O) at 15 days after infection. Notice the emission of a pseudopod prolongation from $T$. vivax $(\triangle)$ and the adhesion of $T$. vivax trypomastigote to RBCs $(\Rightarrow)$. Bar $=1.4 \mu \mathrm{m}$.

[27]. Furthermore, their involvement in the adhesion of $T$. vivax to the proboscide of Tsetse fly (Glossina fuscipes) has been documented [28]. The emission of these filamentous material and filopodia of parasitic origin has been described in phagocytes of cattle infected with T. vivax [29] and in the adhesion of $T$. congolense to endothelial cells from bovine aorta [30].

According to Rossi [13], filopodia and filamentous material help the trypanosome-RBC interaction in a process that is mediated by receptors on the erythrocyte surface. Additionally, the filamentous material could act by promoting the establishment of zip-type connections or hemidesmosome formations as it has been described in the adhesion of $T$. congolense to bovine endothelial cells [30]. Similarly, T. vivax is capable of developing this zip-type connection (Figure 12) and filopodia (Figure 3).

The close contact between trypanosomes and $\mathrm{RBC}$ via sialic acid receptors causes injuries to erythrocyte membranes at the point of contact [11]. In addition to the aforementioned $\mathrm{RBC}$ injuries, the apparent membrane fusion, changes in

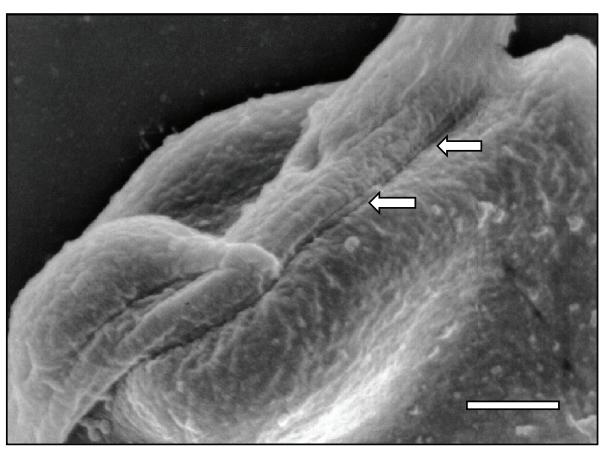

FIGURE 11: Scanning electron micrograph showing a large area $(\Rightarrow)$ of T. vivax in close contact to an erythrocyte at 30 days after infection. Bar $=0.8 \mu \mathrm{m}$.

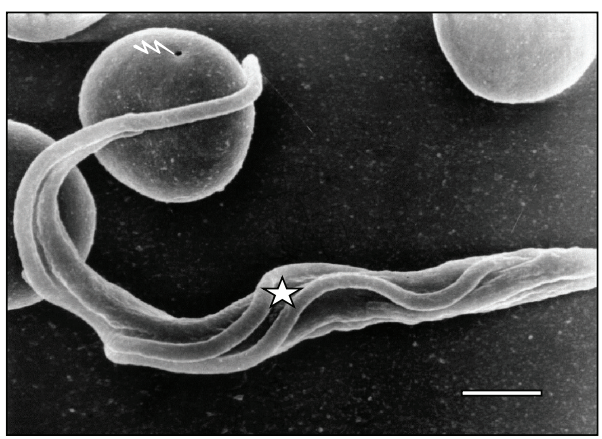

FIGURE 12: Scanning electron micrograph of a T. vivax trypomastigote in division process ( $\downarrow$ ) at 45 days of infection. Note the presence of holes on the RBC surface $(\xi)$ and its round-morphology. Bar $=$ $2.0 \mu \mathrm{m}$.

the oligosaccharide composition of the surface of RBC, and mechanical damage "pinching out" caused by the motility of the trypanosomes in the bloodstream [13, 17, 31] induce ultrastructural, biochemical, and antigenic alterations of the RBC, which increases erythrophagocytosis, as shown in Figure 16.

At the level of the RBC plasma membrane, the modification of its composition by trypanosomal antigens, such as neuraminidases [13], activates effector mechanisms of the immune system leading to the formation and adsorption of antigen-antibody complexes and complements on the surface [32]. This mechanism could explain the occurrence of holes in the RBC surface as is observed in Figures 15, 16, and 17. Those holes may facilitate erythrolysis and/or recognition and removal of $\mathrm{RBC}$ by mononuclear phagocytic system. A similar response to this erythrophagocytosis is the autoimmune mechanism observed in alterations of horse muscles naturally infected with T. evansi [33].

Furthermore, the action of biologically active substances secreted [34] or derived from live or dead trypanosomes [3537], particularly sialidase secreted/excreted from T. vivax, in the bloodstream $[18,37,38]$ contributes to the intravascular erythrophagocytosis [12, 38] described in this paper (Figures 17 and 18). In contrast, changes in the glycocalyx of RBCs 


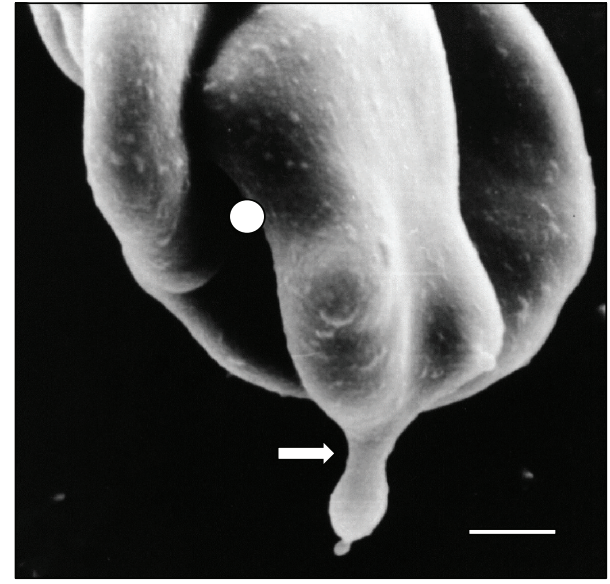

FIGURE 13: High resolution micrograph of a sheep RBC cluster showing a deformed RBC $(\bigcirc)$ with small vesicles and emission of a pseudopod $(\Rightarrow)$ at 15 days of infection. Bar $=1.3 \mu \mathrm{m}$.

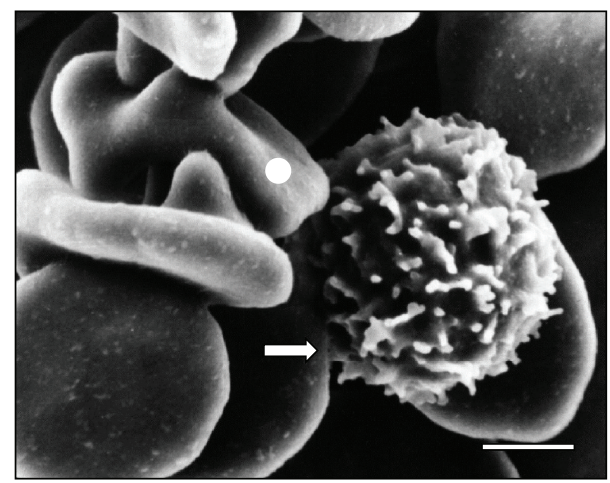

FIgURE 14: Adhesion $(\Rightarrow)$ of one WBC to a deformed RBC $(\bigcirc)$ in the peripheral blood of sheep at 15 days of infection with T. vivax. Bar $=1.0 \mu \mathrm{m}$.

induce extravascular erythrophagocytosis mediated by the mononuclear phagocyte system $[10,12,39-41]$.

Sialidases secreted/excreted by trypanosomes have the ability to remove sialic acid residues from the RBC glycocalyx, enabling glycoconjugate degradation and elimination of fatty acids from cell membranes by other biologically active substances such as proteases, glycosidases, and phospholipases [15, 42, 43]. In this sense, Guegan et al. [18] characterized a multigenic family of transsialidases in $T$. vivax $\mathrm{Y} 486$, some of which are released and able to induce erythrophagocytosis by desialylating the glycophorins.

Cluster formations of thrombi composed of RBC and leukocytes (Figures 14 and 15) have also been described in infections caused by T. brucei and T. evansi and may complicate the pathophysiology of the ovine trypanosomosis caused by $T$. vivax. The systemic complications triggered by anemia together with microthrombi of parasitic origin not only compromise the normal gas and metabolites exchange between blood and host tissues by way of the occlusion of the vascular lumen of capillary, but also contribute to the cell

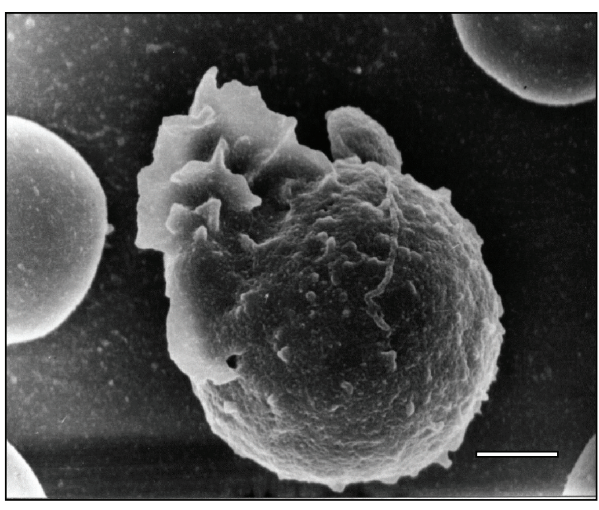

FIGURE 15: Electron micrograph showing an activated WBC in peripheral blood of a sheep at 15 days after infection with $T$. vivax. Bar $=2.5 \mu \mathrm{m}$.

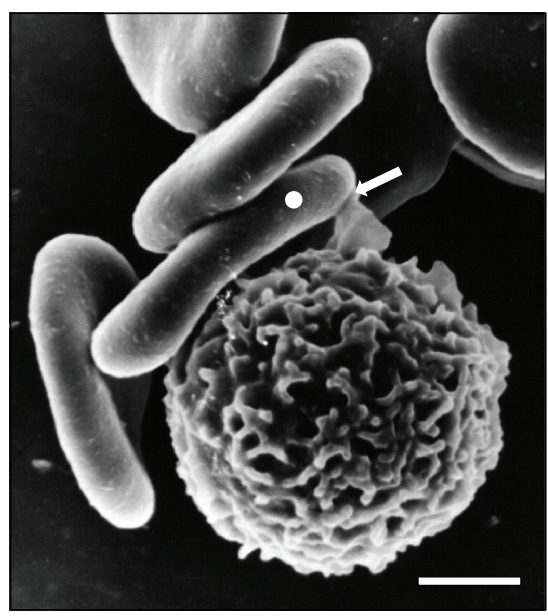

Figure 16: Adhesion $(\Rightarrow)$ of WBC to RBC cluster $(\bigcirc)$ in sheep peripheral blood at 15 days of infection with T. vivax. $\mathrm{Bar}=2.0 \mu \mathrm{m}$.

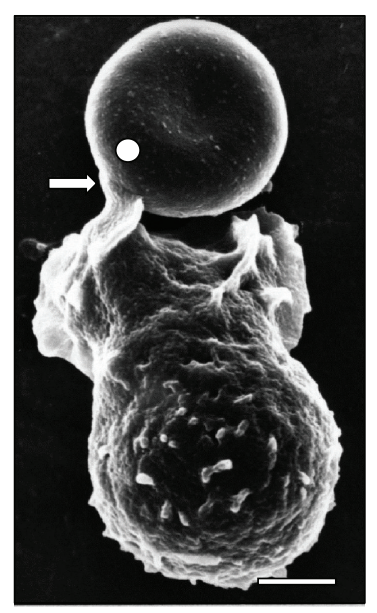

FIgure 17: Phagocytosis $(\Rightarrow)$ of a RBC $(\bigcirc)$ by an activated WBC in peripheral blood of a sheep at 15 days of infection with T. vivax. Bar $=3.0 \mu \mathrm{m}$. 


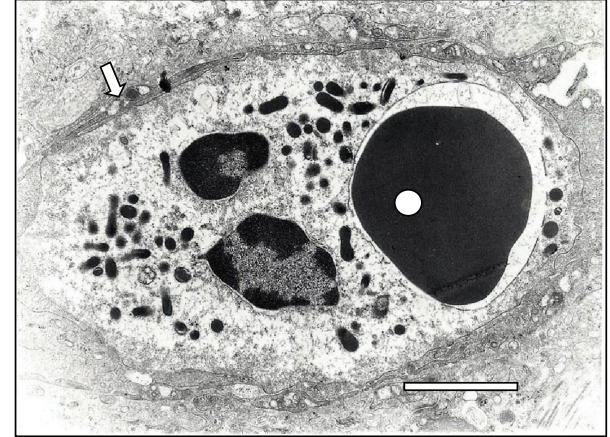

FIGURE 18: Transmission electron microscopy of a RBC phagocytosed $(\bigcirc)$ by a polymorphonuclear cell-neutrophil $(\Rightarrow)$ in the liver of a sheep infected with T. vivax at 15 days. Notice the RBC inside a phagocytic vacuole surrounded by lysosomes. Bar $=1.5 \mu \mathrm{m}$.

necrosis aggravated by endothelial alterations that occur in the disease [12, 13, 41, 44, 45].

Forty-five years ago, Goodwin [31] pointed out that abnormalities of the RBC in trypanosomosis are a consequence of changes that occur in the small blood vessels. With the Venezuelan strain of T. evansi, this alteration in vessels was observed by Finol et al. [45]. Moreover, these authors concluded that the observed alterations on vessels contribute to modifications of the RBC morphological and cytoskeletal structure. The proteolytic lysosomal enzymes released into the circulation system from trypanosomes cleave sialic acid fractions [46] resulting in the vascular endothelium adopting a tortuous shape [47]. While observing the SEM images of sheep tissue experimentally infected with $T$. vivax, we found occurrences of the aforementioned endothelium damage in small vessels.

In experimental infection of mice with T. evansi, changes such as thickening of the basement membrane, proliferation, and vacuolization of endothelial cells and mechanical damage for action of trypanosome flagella and bodies also contribute in the modification of the erythrocyte cytoskeleton structure and morphology [13, 44, 47].

Furthermore, as it has been described in the infections of Camelus dromedarius [48] and rats with T. evansi [49], the infection of sheep with $T$. vivax could generate an oxidative stress with the generation of free radicals and superoxide reactive species that attack the proteins and lipid membranes with osmotic fragility. The peroxidation of lipids determines the degradation of polyunsaturated fatty acids with the interruption of the plasma membrane and a concomitant loss of its basic functions and features, as was described by a different author [15, 50, 51].

The RBC alterations described in this study, like emission of filopodia, vesicles, roughness, and holes on the erythrocyte surface are similar compared to those reported in T. brucei [12] and T. evansi infections [13].

\section{Conclusion}

The adhesion of Trypanosoma vivax (LIEM-176) to sheep erythrocytes described in this study is the first evidence for T. vivax infection. Moreover, the presence of holes and vesicles caused by the adhesion to RBC is an important factor to be considered in parasite-host interactions and contributes to anemia during trypanosomosis.

\section{Competing Interests}

The authors (Alpidio A. Boada-Sucre, Marcello Salvatore Rossi Spadafora, Lucinda M. Tavares-Marques, Héctor J. Finol, and Armando Reyna-Bello) declare that there are no competing interests regarding the publication of this paper.

\section{Acknowledgments}

This research was supported by Project G-98003462-Fondo Nacional de Ciencia, Tecnología e Innovación (FONACIT), Caracas, Venezuela, and the Instituto de Estudios Científicos y Tecnológicos from Universidad Nacional Experimental Simón Rodríguez. The authors thank Beatriz Cajade for critical reading of this paper.

\section{References}

[1] M. I. Gonzatti, B. González-Baradat, P. M. Aso, and A. ReynaBello, "Trypanosoma (Duttonella) vivax and typanosomosis in Latin America: secadera/huequera/cacho hueco," in Trypanosomes and Trypanosomiasis, S. Magez and M. Radwanska, Eds., pp. 261-285, Springer, 2014.

[2] M. Desquesnes, Livestock Trypanosomoses and Their Vectors in Latin America, OIE, Paris, France, 4th edition, 2004.

[3] E. Elhassan, B. O. Ikede, and O. Adeyemo, "Trypanosomosis and reproduction: I. Effect of Trypanosoma vivax infection on the oestrous cycle and fertility in the ewe," Tropical Animal Health and Production, vol. 26, no. 4, pp. 213-218, 1994.

[4] B. J. S. Batista, C. M. F. Rodrigues, H. A. García et al., "Association of Trypanosoma vivax in intracellular sites with central nervous system lesions and changes in cerebrospinal fluid in experimentally infected goats," Veterinary Research, vol. 42, no. 63, pp. 1-7, 2011.

[5] J. S. Batista, F. Riet-Correa, M. M. G. Teixeira, C. R. Madruga, S. D. V. Simões, and T. F. Maia, "Trypanosomiasis by Trypanosoma vivax in cattle in the Brazilian semiarid: description of an outbreak and lesions in the nervous system," Veterinary Parasitology, vol. 143, no. 2, pp. 174-181, 2007.

[6] G. J. N. Galiza, H. A. García, A. C. O. Assis et al., "High mortality and lesions of the central nervous system in trypanosomosis by Trypanosoma vivax in Brazilian hair sheep," Veterinary Parasitology, vol. 182, no. 2-4, pp. 359-363, 2011.

[7] T. M. Silva, R. G. Olinda, C. M. Rodrigues et al., "Pathogenesis of reproductive failure induced by Trypanosoma vivax in experimentally infected pregnant ewes," Veterinary Research, vol. 44, article 1, 2013.

[8] T. S. G. A. M. Van den Ingh, D. Zwart, A. S. J. P. A. M. Van Miert, and A. J. H. Schotman, "Clinico-pathological and pathomorphological observations in Trypanosoma vivax infection cattle," Veterinary Parasitology, vol. 2, no. 3, pp. 237-250, 1976.

[9] K. A. N. Esievo and D. I. Saror, "Immunochemistry and immunopathology of animal trypanosomiasis," Veterinary Bulletin, vol. 61, pp. 755-777, 1991. 
[10] V. O. Anosa, "Haematological and biochemical changes in human and animal trypanosomiasis Part I," Revue D'élevage et de Médecine Vétérinaire des Pays Tropicaux, vol. 41, no. 1, pp. 65-78, 1988.

[11] A. Mbaya, H. Kumshe, and C. Okwudiri-Nwosu, "The mechanism of anaemia in trypanosomosis: a review," in Anemia, D. Silverberg, Ed., pp. 269-282, In Tech, 2012.

[12] V. O. Anosa and J. J. Kaneko, "Pathogenesis of Trypanosoma brucei infection in deer mice (Peromyscus maniculatus): hematologic, erythrocyte biochemical, and iron metabolic aspects," American Journal of Veterinary Research, vol. 44, no. 4, pp. 639644, 1983.

[13] S. M. S. Rossi, Trypanosoma evansi: estudios parasitológicos, ultraestructurales y quimioterapéuticos en la infección experimental del ratón [Ph.D. thesis], Facultad de Ciencias, Universidad Central de Venezuela, Caracas, Venezuela, 2009.

[14] G. C. Jenkins, "Effects of trypanosomes on the haemopoietic system," Transactions of the Royal Society of Tropical Medicine and Hygiene, vol. 74, no. 2, pp. 268-270, 1980.

[15] I. O. Igbokwe, "Mechanism of cellular injury in African trypanosomiasis," Veterinary Bulletin, vol. 64, pp. 611-620, 1994.

[16] J. Naessens, H. Kitani, Y. Yagi, K. Sekikawa, and F. Iraqqi, "TNF- $\alpha$ mediates the development of anaemia in a murine Trypanosoma bruceirhodesiense infection, but not the anaemia associated with a murine T. congolense infection," Clinical \& Experimental Immunology, vol. 139, no. 3, pp. 403-410, 2005.

[17] L. E. J. Huson, E. Authié, A. F. Boulangé, J. P. D. Goldring, and T. H. T. Coetzer, "Modulation of the immunogenicity of the Trypanosoma congolense cysteine protease, congopain, through complexation with $\alpha 2$-macroglobulin," Veterinary Research, vol. 40, article 52, 2009.

[18] F. Guegan, N. Plazolles, T. Baltz, and V. Coustou, "Erythrophagocytosis of desialylated red blood cells is responsible for anaemia during Trypanosoma vivax infection," Cellular Microbiology, vol. 15, no. 8, pp. 1285-1303, 2013.

[19] L. E. González, J. A. García, C. Núñez et al., “Trypanosoma vivax: a novel method for purification from experimentally infected sheep blood," Experimental Parasitology, vol. 111, no. 2, pp. 126-129, 2005.

[20] G. Greif, M. P. de Leon, G. Lamolle et al., “Transcriptome analysis of the bloodstream stage from the parasite Trypanosoma vivax," BMC Genomics, vol. 14, article 149, 2013.

[21] E. Gómez-Piñeres, A. A. Boada-Sucre, A. Bretaña, M. Contreras-Bretaña, F. García, and A. Reyna-Bello, "Comparative morfometric of five Venezuelan Trypanosoma vivax isolates," Revista de la Facultad de Ciencias Veterinarias de la Universidad Central de Venezuela, vol. 55, no. 1, pp. 25-33, 2014.

[22] Z. Brener, "Therapeutic activity and criterion of cure on mice experimentally infected with Trypanosoma cruzi," Revista do Instituto de Medicina Tropical de São Paulo, vol. 4, pp. 389-396, 1962.

[23] A. A. Boada-Sucre, H. De Stefano, B. González, H. Soto, S. Godoy, and A. Bretaña, "Microscopía electrónica de barrido de las alteraciones presentes en los espermatozoides de toros mestizos Siboney," Revista Cientifica FCV-LUZ, vol. 9, no. 3, pp. 235-242, 1999.

[24] M. Mendoza, G. L. Uzcanga, R. Pacheco et al., "Anti-VSG antibodies induce an increase in Trypanosoma evansi intracellular $\mathrm{Ca}^{2+}$ concentration," Parasitology, vol. 135, no. 11, pp. 1303-1315, 2008.
[25] R. F. Macadam and W. J. Herbert, "Fine structural demonstration of cytoplasmic protrusions (Filopodia) in Trypanosomes," Experimental Parasitology, vol. 27, no. 1, pp. 1-8, 1970.

[26] K. Vickerman, "The mode of attachment of Trypanosoma vivax in the proboscis of the tsetse fly Glossina fuscipes: an ultrastructural study of the epimastigote stage of the trypanosome," Journal of Protozoology, vol. 20, no. 3, pp. 394-404, 1973.

[27] R. Hernández-Páez, "Consideraciones ultraestructurales sobre el Trypanosoma venezuelense, Mesnil 1910; Aspecto morfológico normal del Trypanosoma venezuelense," Revista Facultad de Ciencias Veterinarias, UCV, vol. 28, pp. 83-106, 1980.

[28] C. Hoare, The Trypanosomes of Mammals. A Zoological Monograph, Blackwell Scientific Publications, Oxford, UK, 1972.

[29] D. J. Williams, L. L. Logan-Henfrey, E. Authie, C. Seely, and F. McOdimba, "Experimental infection with a haemorrhagecausing Trypanosoma vivax in n'dama and boran cattle," Scandinavian Journal of Immunology, vol. 36, supplement 1, pp. 34-36, 1992.

[30] A. Hemphill and C. A. Ross, "Flagellum-mediated adhesion of Trypanosoma congolense to bovine aorta endothelial cells," Parasitology Research, vol. 81, no. 5, pp. 412-420, 1995.

[31] L. G. Goodwin, "The pathology of African trypanosomiasis," Transactions of the Royal Society of Tropical Medicine and Hygiene, vol. 64, pp. 797-812, 1970.

[32] D. Bratosin, J. Mazurier, J. P. Tissier et al., "Cellular and molecular mechanisms of senescent erythrocyte phagocytosis by macrophages. A review," Biochimie, vol. 80, no. 2, pp. 173195, 1998.

[33] M. E. Quiñones-Mateu, H. J. Finol, L. E. Sucre, and S. H. Torres, "Muscular changes in Venezuelan wild horses naturally infected with Trypanosoma evansi," Journal of Comparative Pathology, vol. 110, no. 1, pp. 79-89, 1994.

[34] M. Rossi, A. Bremo, M. Gonzatti, and S. Giardina, "Trypanosoma evansi secretes proteins to the extracelular medium," in Proceedings of the XXV Convención Anual de AsoVAC, Universidad Simón Bolívar, Caracas, Venezuela, November 1995.

[35] G. Knowles, G. Abebe, and S. J. Black, "Peptidase in the plasma of mice infected with Trypanosoma brucei brucei," Parasitology, vol. 95, pp. 291-300, 1987.

[36] D. M. Okenu, K. N. Opara, R. I. Nwuba, and M. Nwagwu, "Purification and characterization of an extracellular release protease of Trypanosoma brucei," Parasitology Research, vol. 85, no. 5, pp. 424-428, 1999.

[37] K. A. N. Esievo, "In vitro production of neuraminidase (sialidase) by Trypanosoma vivax," in Proceedings of the OAU/STRC International Council for Trypanosomiasis Research and Control, pp. 205-210, Yaounde, Cameroum, 1979.

[38] B. A. Kimeto, G. M. Mugera, and P. N. Nyaga, "Haemorrhagic pancarditis in cattle infected with Trypanosoma vivax," Veterinary Parasitology, vol. 34, no. 4, pp. 295-301, 1990.

[39] K. A. N. Esievo and D. I. Saror, "Leukocyte response in experimental Trypanosoma vivax infection in cattle," Journal of Comparative Pathology, vol. 93, no. 2, pp. 165-169, 1983.

[40] V. O. Anosa, L. L. Logan-Henfrey, and M. K. Shaw, "A light and electron microscopic study of changes in blood and bone marrow in acute hemorrhagic Trypanosoma vivax infection in calves," Veterinary Pathology, vol. 29, no. 1, pp. 33-45, 1992.

[41] S. M. S. Rossi, A. A. Boada-Sucre, G. Hernández et al., "Ultrastructural analysis of liver in mice experimentally infected with a Venezuelan isolated of Trypanosoma evansi (Kinetoplastida: 
Trypanosomatidae)," Acta Microscópica, vol. 17, no. 2, pp. 5-12, 2008.

[42] A. Samad, B. Licht, M. E. Stalmach, and A. Mellors, "Metabolism of phospholipids and lysophospholipids by Trypanosoma brucei," Molecular and Biochemical Parasitology, vol. 29, no. 2-3, pp. 159-169, 1988.

[43] M. Engstler and R. Schauer, "Sialidases from African Trypanosomes," Parasitology Today, vol. 9, no. 6, pp. 222-225, 1993.

[44] M. Rossi, A. Boada-Sucre, H. J. Finol et al., "Ultrastructural alterations in the adrenal gland cortex of mice experimentally infected with a Venezuelan isolate of Trypanosoma evansi," Journal of Submicroscopic Cytology and Pathology, vol. 31, no. 4, pp. 509-513, 1999.

[45] H. J. Finol, A. A. Boada-Sucre, M. Rossi, and F. Tejero, "Skeletal muscle ultrastructural pathology in mice infected with Trypanosoma evansi," Journal of Submicroscopic Cytology and Pathology, vol. 33, no. 1-2, pp. 65-71, 2001.

[46] G. M. W. Cook, D. H. Heard, and G. V. F. Seaman, "A sialomucopeptide liberated by trypsin from the human erythrocyte," Nature, vol. 188, no. 4755, pp. 1011-1012, 1960.

[47] A. A. Boada-Sucre, Histopatología y patología ultraestructural de la glándula adrenal, el hígado y el testículo de ovinos infectados experimentalmente con Trypanosoma vivax [Ph.D. thesis], Facultad de Ciencias. Universidad Central de Venezuela, Caracas, Venezuela, 2009.

[48] M. A. Saleh, M. B. Al-Salahy, and S. A. Sanousi, "Oxidative stress in blood of camels (Camelus dromedaries) naturally infected with Trypanosoma evansi," Veterinary Parasitology, vol. 162, no. 3-4, pp. 192-199, 2009

[49] A. Mijares, J. Vivas, C. Abad et al., "Trypanosoma evansi: effect of experimental infection on the osmotic fragility, lipid peroxidation and calcium-ATPase activity of rat red blood cells," Experimental Parasitology, vol. 124, no. 3, pp. 301-305, 2010.

[50] B. A. Freeman and J. D. Crapo, "Biology of disease: free radicals and tissue injury," Laboratory Investigation, vol. 47, no. 5, pp. 412-426, 1982.

[51] I. A. Umar, E. Ogengy, D. Okodaso et al., "Amelioration of anaemia and organ damage by combined intraperitoneal administration of vitamin A and C to Trypanosoma brucei brucei infected rats," African Journal of Biotechnology, vol. 6, no. 18, pp. 2083-2086, 2007. 


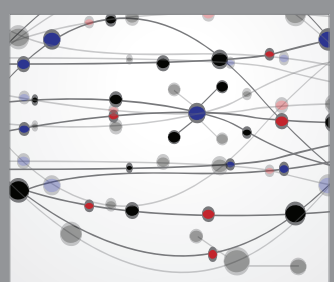

The Scientific World Journal
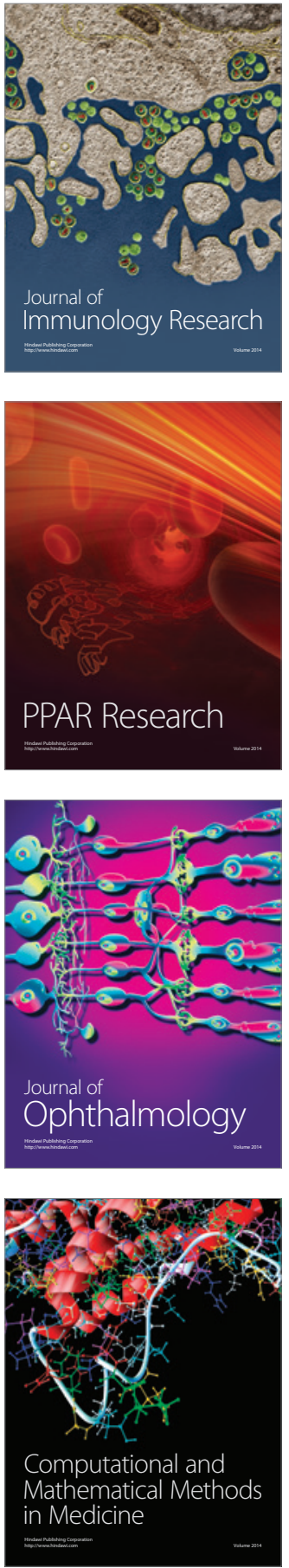

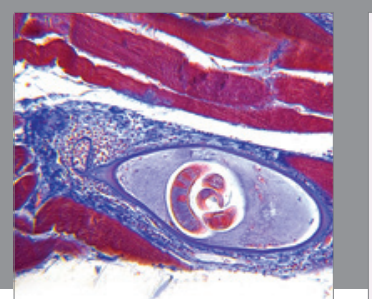

Gastroenterology Research and Practice

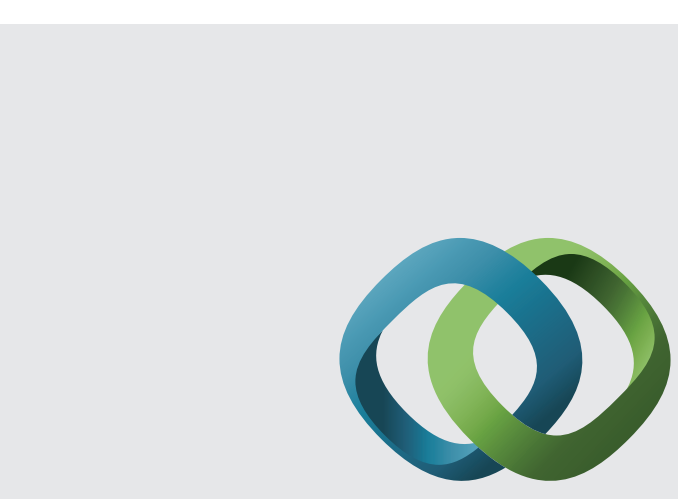

\section{Hindawi}

Submit your manuscripts at

http://www.hindawi.com
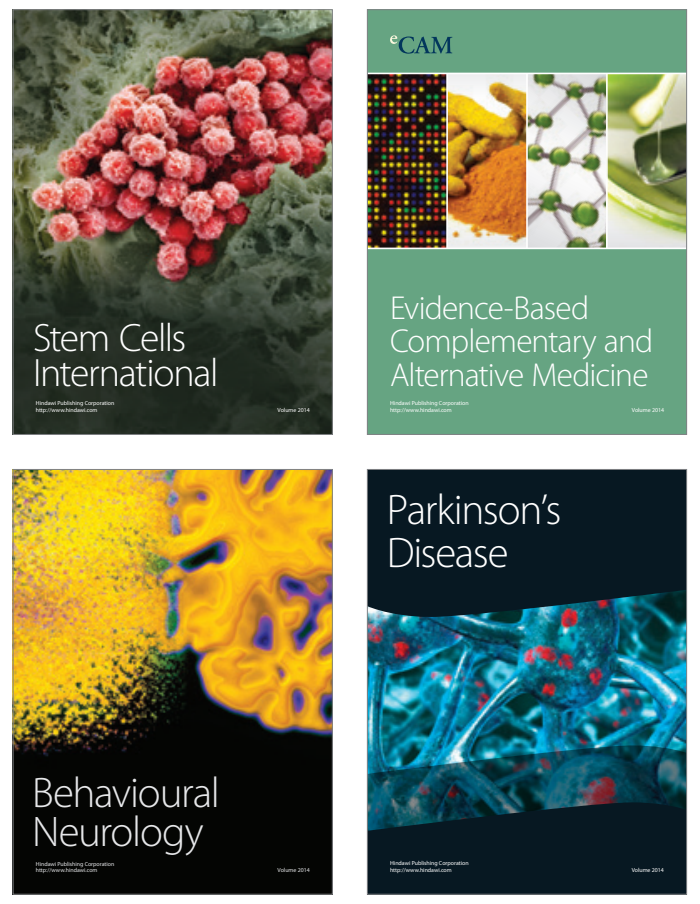
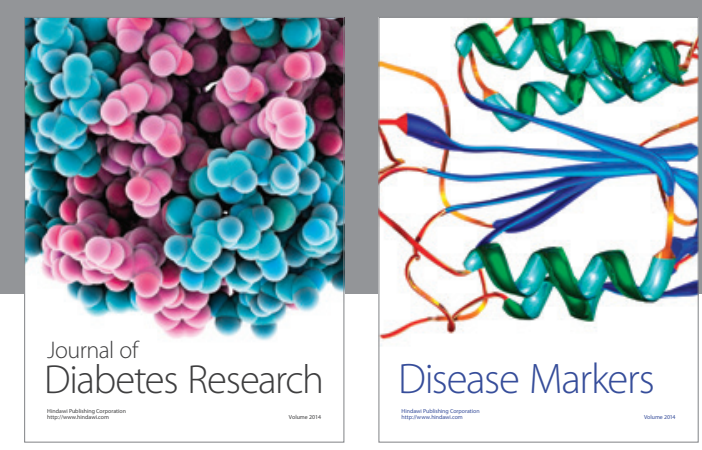

Disease Markers
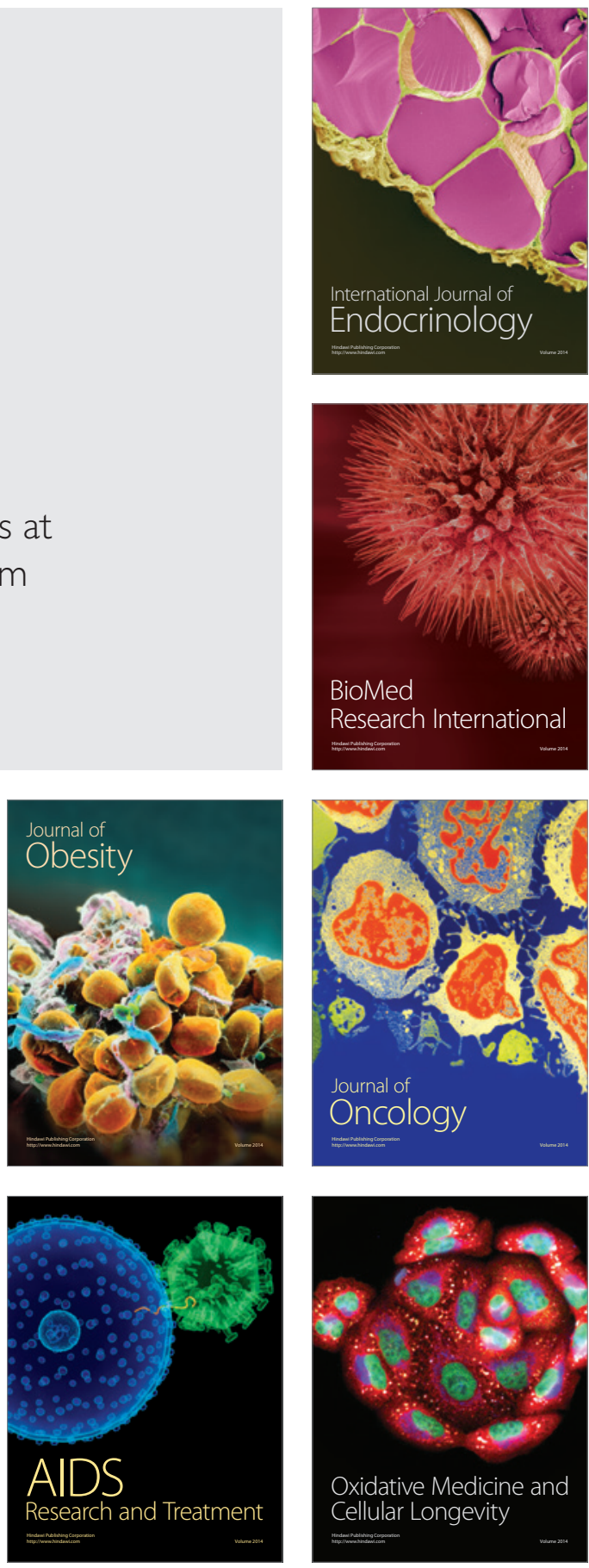